\title{
Molecular Mechanism of Vegetative Growth Advantage in Allotriploid Populus
}

\author{
Kang Du ${ }^{1,+} \mathbb{D}$, Ting Liao ${ }^{2,+}$, Yongyu Ren ${ }^{1,3,4}$, Xining Geng ${ }^{1,3,4}$ and Xiangyang Kang $1,3,4, * \mathbb{C}$ \\ 1 Beijing Advanced Innovation Center for Breeding by Molecular Design, Beijing Forestry University, No. 35, \\ Qinghua East Road, Haidian District, Beijing 100083, China; dukang@bjfu.edu.cn (K.D.); \\ yongyuren@bjfu.edu.cn (Y.R.); gengxn@bjfu.edu.cn (X.G.) \\ 2 Beijing Academy of Forestry and Pomology Sciences No. 12 A Rui Wang Fen, Fragrance Hills Haidian \\ District, Beijing 100093, China; liaoting@baafs.net.cn \\ 3 Key Laboratory of Genetics and Breeding in Forest Trees and Ornamental Plants, Ministry of Education, \\ Beijing Forestry University, No. 35, Qinghua East Road, Haidian District, Beijing 100083, China \\ 4 National Engineering Laboratory for Tree Breeding, College of Biological Sciences and Technology, Beijing \\ Forestry University, No. 35, Qinghua East Road, Haidian District, Beijing 100083, China \\ * Correspondence: kangxy@bjfu.edu.cn; Tel.: +86-10-6233-6168 \\ + These authors contributed equally to this work.
}

Received: 19 November 2019; Accepted: 7 January 2020; Published: 10 January 2020

\begin{abstract}
Allotriploid poplar has a prominent vegetative growth advantage that impacts dramatically on lumber yield. The growth regulation is complex which involves abundant genes, metabolic and signaling pathways, while the information about the functional control process is very little. We used high-throughput sequencing and physiological index measurement to obtain a global overview of differences between allotriploid and diploid Populus. The genes related to plant growth advantage show a higher expression compared to diploid, and most of them are revolved around hormones, photosynthesis and product accumulation. Thus, allotriploid Populus showed more efficient photosynthesis, carbon fixation, sucrose and starch synthesis, and metabolism as well as augmented biosynthesis of auxin, cytokinin, and gibberellin. These data enable the connection of metabolic processes, signaling pathways, and specific gene activity, which will underpin the development of network models to elucidate the process of triploid Populus advantage growth.
\end{abstract}

Keywords: allotriploid; vegetative growth advantage; regulatory mechanism; dosage effect

\section{Introduction}

Polyploid plants often show prominent vegetative growth advantages [1,2]. These growth advantages include, but are not limited to, larger leaf area and cell size, more vigorous growth, and greater plant size [2,3]. For example, the leaf area and cell size were usually larger in Arabidopsis tetraploid plants than in diploid plants [2]. In Zea mays, triploid plants grew stronger than diploid plants [3,4], which was similar to Medicago tetraploids [5]. Among trees, Populus triploids manifest more vigorous growth and greater superiority than diploids. The biomass of triploids can reach 2-3 times that of diploids [6,7]. To maintain these growth advantages, polyploids demand more carbohydrates from greater assimilation of photosynthetic carbon [8-11]. According to previous reports, photosynthesis and chlorophyll content was higher in polyploids than diploids [2,9,12]. Research on different leaf canopy positions of Populus triploid populations suggested that triploid populations had a larger leaf area, higher chlorophyll content, and higher rates of photosynthesis compared to diploid populations [13]. However, the opposite can also be true. Tetraploid Triticum aestivum showed less photosynthesis than diploids [14]. 
The vegetative growth advantage in polyploids is certainly related to the increased genome size $[15,16]$. The question raised is what is the role of increased genome size in regulating genetics during vegetative growth? Differences in gene expression changes between polyploids and diploids have been documented in many plant species $[17,18]$. Previous research has reported that the expression of genes related to chlorophyll biosynthesis and sucrose and starch biosynthesis and metabolism was upregulated in Arabidopsis tetraploids compared with diploids. Growth advantages in Arabidopsis tetraploid plants were related to the circadian clock. During the day, the repressors LHY (LATE ELONGATED HYPOCOTYL) and CCA1 (CIRCADIAN CLOCK ASSOCIATED1) were more inhibited in tetraploid plants than in the parents, which resulted in augmented photosynthesis and starch accumulation [2]. However, the influence of leaf position in a canopy gradient and the relationship between gene expression and miRNAs were not taken into account. Therefore, the molecular mechanisms of the vegetative growth advantage in polyploid plants require further investigation.

Physiological studies showed that two triploid populations (triploid-F and triploid-S) with different heterozygosity have significantly growth advantage than the diploid population. However, there are significant differences between triploid-F and triploid-S triploid populations in tree height, DBH (diameter at breast height) and leaf area [13]. This may be caused by the heterozygosity of parental transmission of gametes from different sources [19], so we selected two triploid populations for full research. Preliminary experiments founded that photosynthetic capacity maintained a high level from the 5th to the 10th leaf and showed stable senescence after the twenty-fifth leaf position. In this study, leaf canopy positions of two Populus allotriploid populations with different $2 \mathrm{n}$ gamete origins, triploid-F and triploid-S, and one diploid population from the same parents were used as the plant material [20]. We obtained the dynamic difference in the development of triploid and diploid leaves. The molecular mechanism of vegetative growth advantage in allotriploid plants was explored.

\section{Results}

\subsection{Transcription Profile of DEGs (Differentially Expressed Genes) and RT-PCR (Real-Time Quantitative Polymerase Chain Reaction) Validation}

Results showed 10,275 differentially expressed genes (DEGs) in total in triploid plants when diploids were used as the baseline. A total of 1911, 2938, and 2986 DEGs in triploid-F plants and 2248, 2272, and 4949 DEGs in triploid-S plants were identified in the 5th, 10th, and 25th leaves, respectively. The numbers of upregulated and downregulated genes in the 5th, 10th, and 25th leaves were shown in Figure 1A. There were fewer upregulated genes than downregulated genes in the 5th leaves of triploid-F plants and in the 5th and 10th leaves of triploid-S plants, whereas there were more upregulated genes than downregulated genes in the 10th and 25th leaves of triploid-F plants and in the 25th leaves of triploid-S plants (Figure 1A). A total of 36 DEGs on different leaf canopy positions were randomly selected for real-time polymerase chain reaction (RT-PCR) verification, and a comparison of the RT-PCR results and the RNA-seq data suggested that trends in changes in expression of most DEGs were in agreement (Figure 1B). 
A

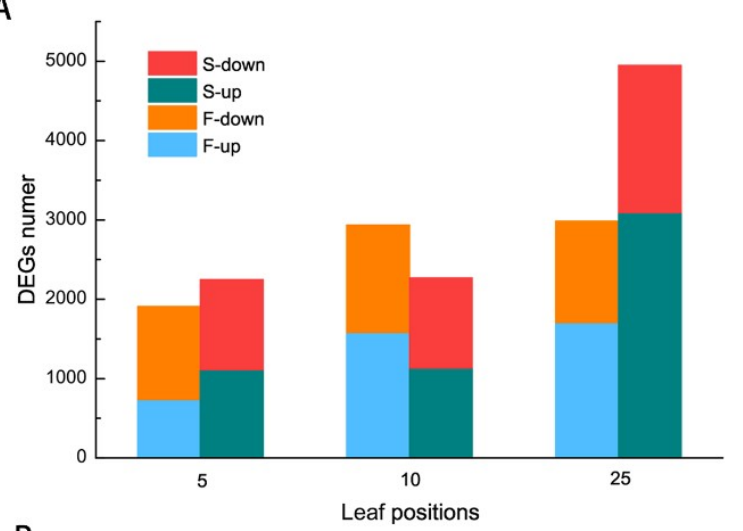

B

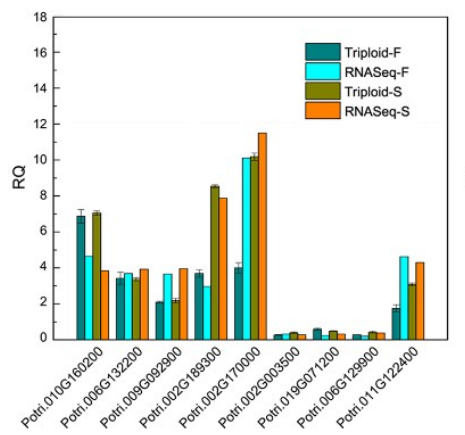

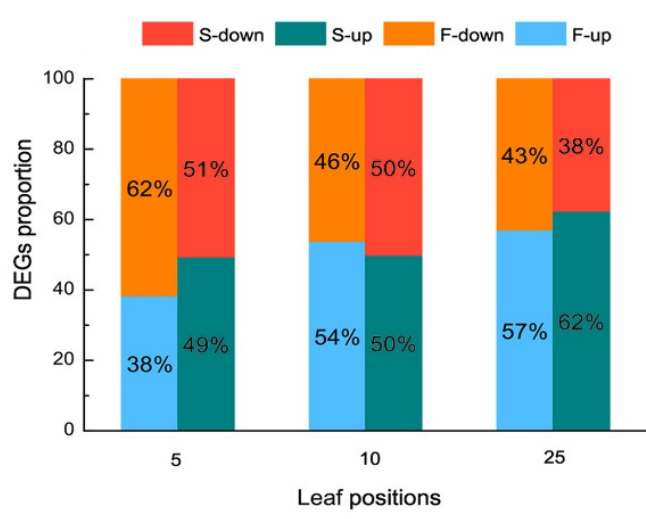

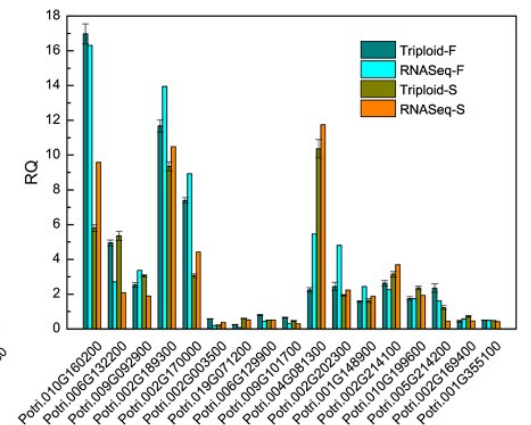

Figure 1. Transcription profile of differentially expresssed genes (DEGs) and real-time polymerase chain reaction (RT-PCR) validation. (A) The numbers and proportions of upregulated and downregulated genes in the 5th, 10th, and 25th leaves of triploid-F and triploid-S plants; (B) RT-PCR verification of randomly selected DEGs in the 5th, 10th, and 25th leaves of triploid-F and triploid-S plants.

\subsection{Chlorophyll Synthesis and Degradation}

A total of 24 genes involved in chlorophyll biosynthesis and metabolism showed a dosage effect and were differentially expressed (Figure 2A) in allotriploid plants compared to diploid plants. Seventeen genes were upregulated in the leaves at different positions of triploid-F and triploid-S plants, including PORA (protochlorophyllide oxidoreductase A), which can catalyze the synthesis of tetrapyrrol, prompting the conversion of protochlorophyll to chlorophyll. In addition, chloroplast and chlorophyll content was significantly greater in Populus allotriploids than diploids (Figure 2B). There were significant differences in numbers of chloroplasts between the 5th and 10th leaves of triploids, although no differences were found among the 5th, 10th, and 25th leaves, which indicates that chloroplasts were dividing between the 5th and 10th leaves of triploids. The number of mesophyll cell chloroplasts was 22.9 and 16.9 in triploids and diploids, respectively; therefore, the number of chloroplasts in triploids was about 1.35 times that in diploids. The chlorophyll content and chloroplast numbers of both triploid Populus was significantly different from that of diploids in the 5th and 10th leaves, but triploid-S plants did not differ from diploid plants in the 25th leaves (Figure 2B). 
$\begin{array}{llllllllll}\text { A } & \text { F-5 } & \text { S-5 } & \text { D-5 } & \text { F-10 } & \text { S-10 } & \text { D-10 } & \text { F-25 } & \text { S-25 } & \text { D-25 }\end{array}$

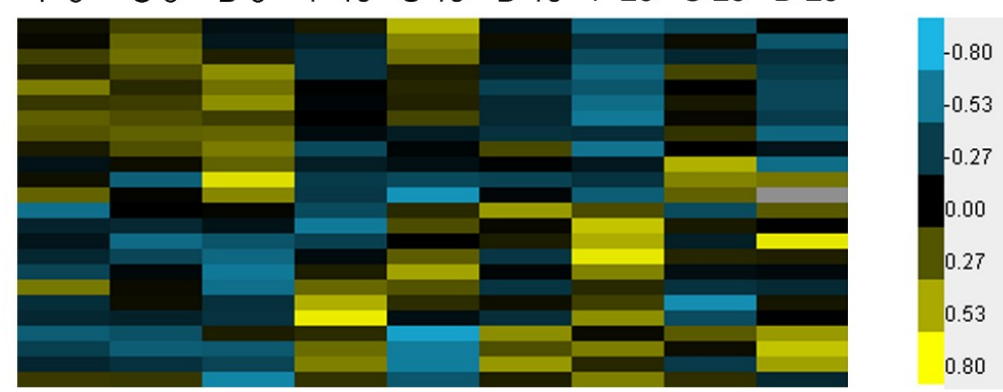

B
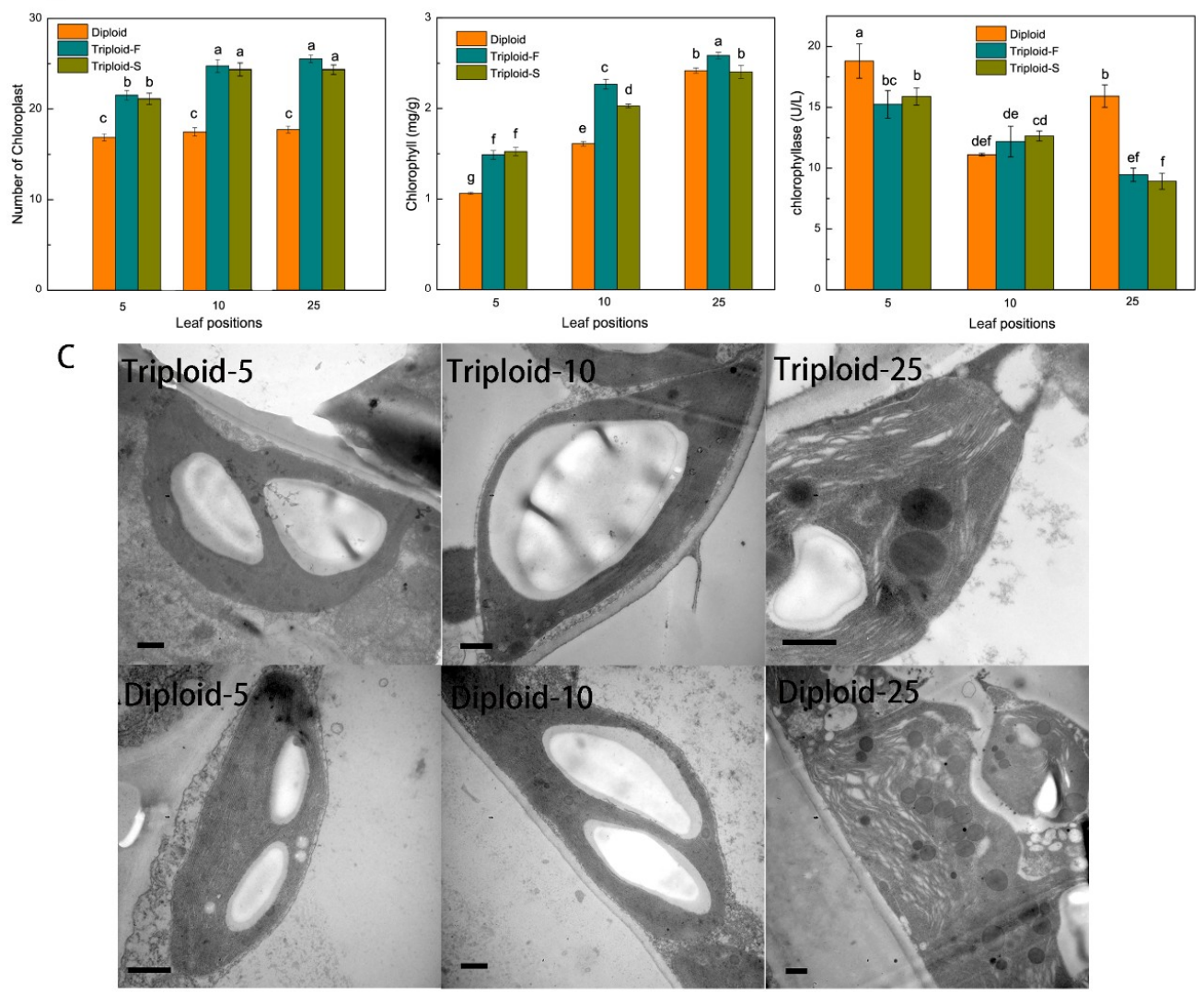

Figure 2. Chlorophyll synthesis and degradation in triploid-F, triploid-S and diploid plants. (A) Differentially expressed genes (DEGs) involved in chlorophyll synthesis and metabolism at different leaf canopy positions when triploid-F and triploid-S plants were compared to diploid plants; (B) The number of chloroplasts, chlorophyll content and chlorophyllase activity in triploid-F, triploid-S and diploid plants, different lowercase letters represent significant differences at $p<0.05$; (C) Chloroplast ultrastructure in the 5th, 10th and 25th leaves in allotriploid and diploid plants. Bar $=10 \mu \mathrm{m}$.

CLH, which is involved in chlorophyll degradation, was significantly downregulated in the 25th leaves of triploid-S plants. At the same time, chlorophyllase activity in the 5th and 25th leaves of triploid-S plants was significantly lower than in the same leaves of diploid plants (Figure 2B). The chloroplast ultrastructure of the 5 th and 10th leaves did not differ between allotriploid and diploid plants. Chloroplasts were full of starch granules, starch granules in allotriploid plants were greater than in diploid plants, and the stroma lamella was complete (Figure 2C). However, compared to allotriploid plants, a wider range of osmiophilic granules were observed and the stroma lamella was more seriously damaged in the 25th leaves of diploid plants (Figure 2C), which indicated that the chloroplast aging rate was slower in allotriploids than in diploids. Therefore, Populus allotriploids showed a larger leaf area, a higher chlorophyll content, and a slower chloroplast aging rate compared to diploid plants. 


\subsection{Photoreaction and Carbon Fixation}

There were 192 DEGs directly involved in or associated with light reaction and $\mathrm{CO}_{2}$ fixation in allotriploids compared to diploids. Of these DEGs, 135 were upregulated in two types of allotriploids and various leaf canopy positions, including the LHC (light harvesting complex) family members, which are involved in in light capture; two thylakoid membrane protein subunits, Psa and Psb family members; and key genes involved in the Calvin cycle, such as GAPDH, FBP, and PRK (Figure 3A). Allotriploid plants showed more efficient light capture, light reaction, and $\mathrm{CO}_{2}$ fixation compared to diploid plants. In addition, Pn was significantly greater in allotriploid plants than in diploid plants in various leaf canopy positions (Figure 3B), consistent with gene expression data. In the leaves below the 25th leaves, allotriploids still maintained a higher Pn, whereas the Pn of diploids decreased more quickly, which again indicates that chloroplast aging was slower in allotriploids than diploids.

A
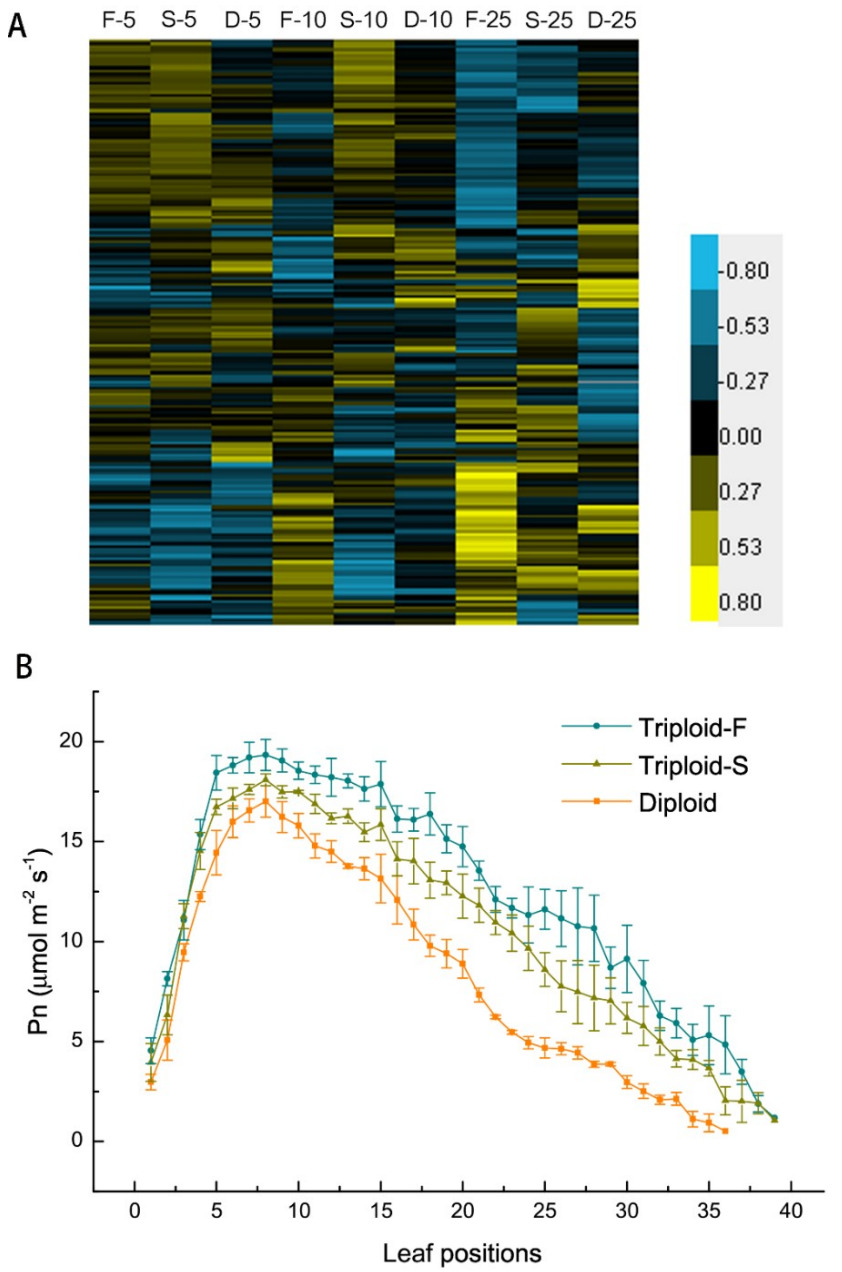

Figure 3. Photosynthesis in in triploid-F, triploid-S and diploid plants. (A) Differentially expressed genes (DEGs) involved in light reaction and carbon fixation on different leaf canopy positions when triploid-F and triploid-S plants were compared to diploid plants; (B) Net rates of photosynthesis on various leaf canopy positions in triploid-F, triploid-S plants and diploid plants.

\subsection{Starch and Sucrose Synthesis and Metabolism}

A total of 118 genes associated with sucrose and starch metabolism showed differential expression patterns in allotriploids compared to diploids at different leaf canopy positions in Populus. Among them, 86 were upregulated in allotriploid plants, including genes involved in sucrose synthesis and degradation, such as SUS and SPS, and genes involved in starch synthesis and decomposition, such as $S S, I S A, A M S, D B E, B A M, A M Y$, and EMB (Figure 4A). At the same time, sugar and starch contents 
were detected in leaves. Sucrose, glucose, and fructose contents were significantly higher in the 5th, 10th, and 25th leaves of the two types of allotriploid plants compared to the diploid plants (Figure 4B). The starch content increased with the increase in leaf position in both allotriploid and diploid plants, whereas there were no differences between the 25th leaves of triploid-F and triploid-S plants (Figure 4B). SUS, SPS, and AMS activity was significantly greater in allotriploid plants than diploid plants at the same leaf position (Figure 4C). In addition, enzyme activity was significantly greater in the 10th and 25th leaves than the 5th leaves (Figure 4C). Most genes related to sucrose and starch synthesis and metabolism in Populus allotriploids showed a dosage effect, which indicates that allotriploids had a greater ability to synthesize and transform sugar and starch.

\section{F-5 S-5 D-5 F-10 S-10 D-10 F-25 S-25 D-25}
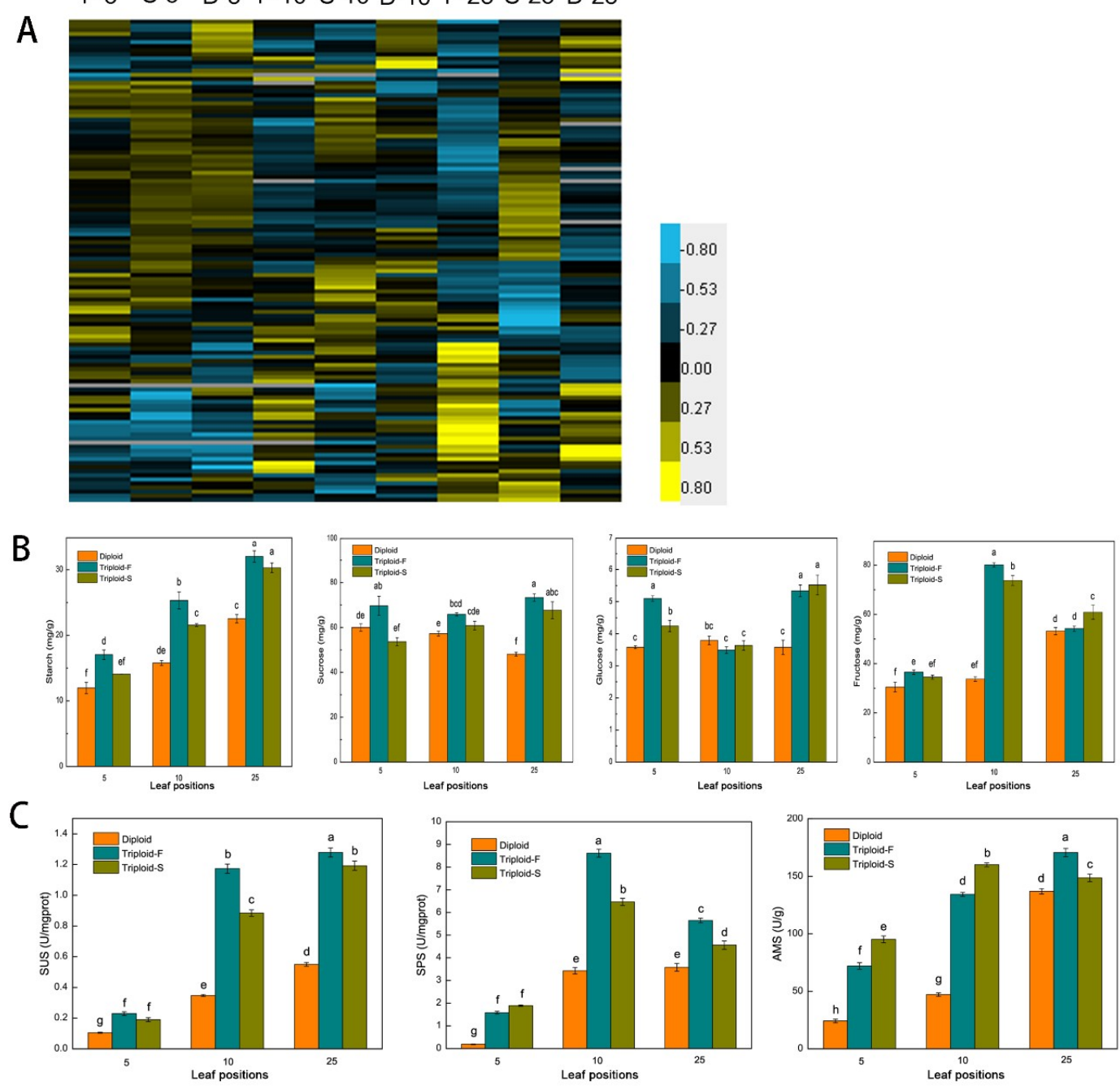

Figure 4. Starch and sucrose synthesis and metabolism in triploid-F, triploid-S and diploid plants. (A) Differentially expressed genes (DEGs) associated with sucrose and starch synthesis and metabolism on different leaf canopy positions when triploid-F and triploid-S plants were compared to diploid plants; (B) Starch, sucrose, glucose and fructose content on different leaf canopy positions when triploid-F and triploid-S plants were compared to diploid plants; (C) SUS, SPS, and AMS enzyme activity on different leaf canopy positions when triploid-F and triploid-S plants were compared to diploid plants. Different lowercase letters represent significant differences at $p<0.05$.

\subsection{Plant Hormone Synthesis and Signal Transduction}

In this study, 207 differentially expressed genes involved in plant hormone synthesis and signal transduction (Figure 5A). Including the auxin related genes ( $A R F s)$, cytokinins degradative genes 
(CKX1) and brassinosteroid signaling positive regulator (BZR1) were upregulated on various leaf canopy positions in allotriploids compared to diploids. The contents of IAA, GA3, zeatin (ZT), and ABA (abscisic acid) were measured in the 5th and 25th leaves of triploid-F and diploid plants. IAA, GA3, and ZT contents were higher in the 5th and 25th leaves, and ABA content lower in the 5th leaves, of triploid-F plants compared to diploid plants, whereas no differences were found between the 25th leaves of triploid-F and diploid plants (Figure 5B). Overall, the expression of genes involved in IAA, cytokinins (CTK), GAs, and brassinosteroids (BRs) synthesis and signal transduction was significantly higher in allotriploids than diploids. These hormones act alone and in concert to regulate vegetative growth advantages in Populus allotriploids.
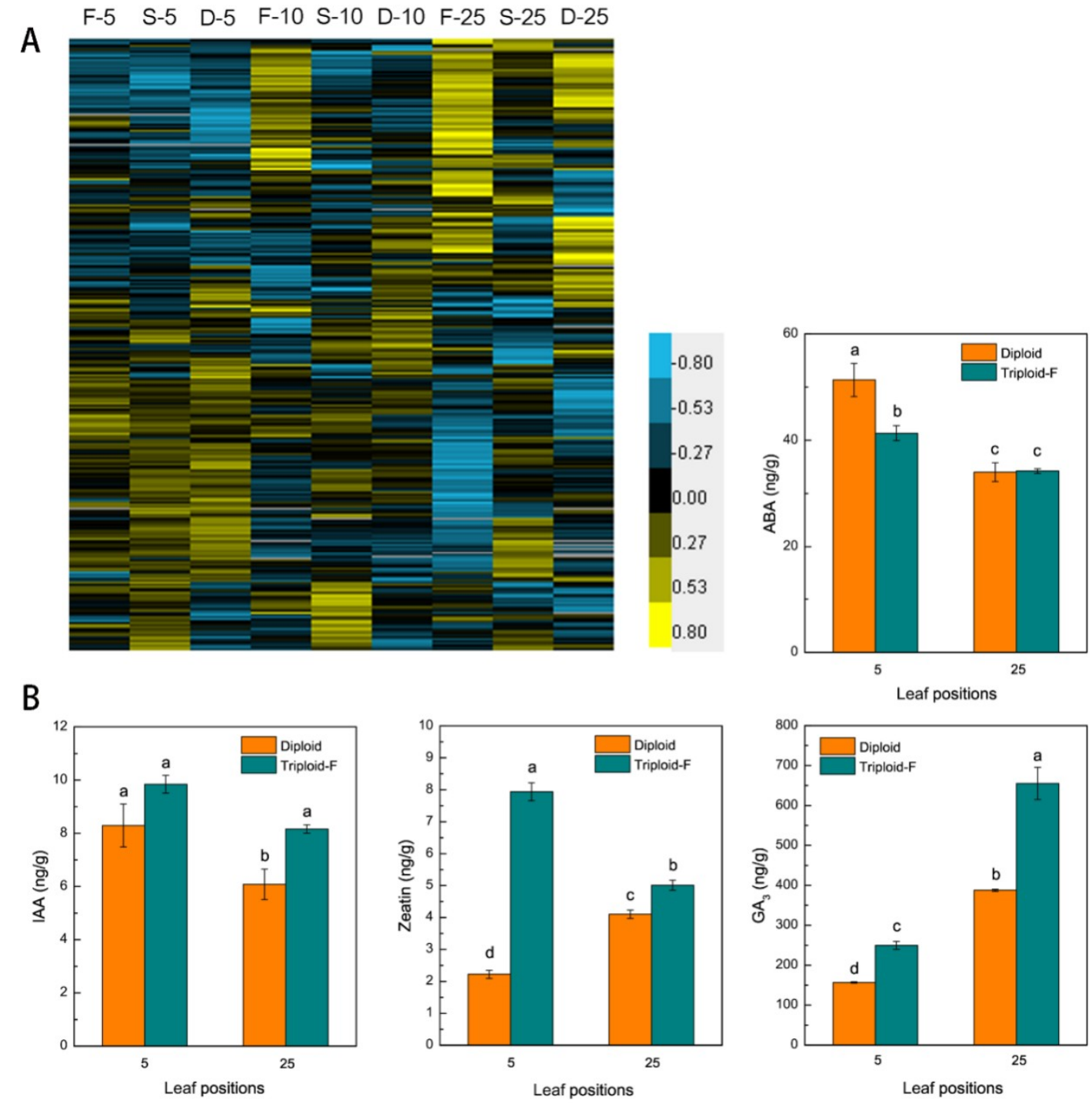

Figure 5. Hormone biosynthesis genes causing the upregulation of hormone in triploids. (A) Differentially expressed genes (DEGs) involved in plant hormone signal transduction on different leaf canopy positions when triploid-F and triploid-S plants were compared to diploid plants; (B) IAA, ZT, GA3 and ABA content in the 5th and 25th leaves of triploid-F and diploid plants. Different lowercase letters represent significant differences at $p<0.05$.

\subsection{Differentially Expressed miRNA Analysis}

A total of 3181 miRNAs were detected by miRNA sequencing on the 5th leaves of allotriploid and diploid plants. Analysis of transcript levels by RT-PCR showed that miRNAs $\left(\mathrm{R}^{2}>0.9, p<0.01\right)$ all displayed high correlation between the small RNA-seq and quantitative measurement suggesting 
that our high-throughput data were reliable (Figure S1). There were 12 (five upregulated, seven downregulated) and 10 (seven upregulated, three downregulated) differentially expressed miRNAs between triploid-F and triploid-S plants compared to diploid plants, respectively, and the fold changes ranged from 4.39 to 100 (Table 1). The target gene expression and function of miRNAs were analyzed using transcriptome data of the same materials. A total of 22 differentially expressed miRNAs could be applied to 227 target gene loci of 155 target genes, and one miRNA applied to 10.32 loci on average. Functional annotation of target genes showed that they were involved in stress defense, lignin synthesis, programmed cell death, response to gibberellins stimulation, regulation of secondary cell-wall synthesis, growth, cell division, and sucrose metabolism processes (Table S1). A total of 15 genes in the 22 target genes were differentially expressed when combined with the transcriptome data, and 14 pairs of miRNA and mRNA showed a negative regulating relationship (Table 2). Target genes directly related to plant vegetative growth characteristics were not found.

To verify the differences in miRNAs regulating the vegetative growth advantage between allotriploid and diploid plants, we used DEGs in the 5th leaves of allotriploid and diploid plants related to chloroplast decomposition, photoreaction, carbon fixation, sucrose, starch synthesis and decomposition, plant hormone synthesis, and signal transduction as target genes and reversed them to identify their corresponding miRNAs. A total of 123 DEGs from triploid-F plants and 113 DEGs from triploid-S plants were involved in or associated with bioprocesses related to vegetative growth. These 123 and 113 vegetative genes were regulated by 54 and 46 miRNAs (Tables S2 and S3), respectively. However, expression of these miRNAs did not differ significantly between allotriploid and diploid plants.

Table 1. Differentially expressed microRNAs in allotriploid and diploid Populus.

\begin{tabular}{|c|c|c|c|c|c|c|}
\hline Group & AccID & Sequence & FC & Style & $p$-Value & FDR \\
\hline \multirow{12}{*}{ F5 vs. D5 } & chr5_13131_mature & acagaatcagagttcacaggcct & 7.76 & up & $3.24 \times 10^{-5}$ & $1.51 \times 10^{-2}$ \\
\hline & chr17_37159_mature & gcatcaatttatcttagtagcca & 6.21 & up & $4.08 \times 10^{-5}$ & $1.51 \times 10^{-2}$ \\
\hline & chr7_17886_mature & gtggatcatgtatttgatgg & 5.46 & up & $1.09 \times 10^{-4}$ & $2.14 \times 10^{-2}$ \\
\hline & ptc-miR169t & gagccaagaatgacttgccgg & 0.07 & down & $2.23 \times 10^{-8}$ & $4.38 \times 10^{-5}$ \\
\hline & chr17_37159_star & tgcaatgtagggaatagatgtg & 9.23 & up & $4.39 \times 10^{-6}$ & $4.32 \times 10^{-3}$ \\
\hline & ptc-miR395k & ctgaagtgtttgggggaactc & 0.18 & down & $7.72 \times 10^{-5}$ & $1.90 \times 10^{-2}$ \\
\hline & ptc-miR395j & ctgaagtgtttgggggaactc & 0.20 & down & $1.72 \times 10^{-4}$ & $3.07 \times 10^{-2}$ \\
\hline & ptc-miR395h & ctgaagtgtttgggggaactc & 0.17 & down & $4.09 \times 10^{-5}$ & $1.51 \times 10^{-2}$ \\
\hline & ptc-miR395f & ctgaagtgtttgggggaactc & 0.17 & down & $4.62 \times 10^{-5}$ & $1.51 \times 10^{-2}$ \\
\hline & ptc-miR395d & ctgaagtgtttgggggaactc & 0.19 & down & $8.91 \times 10^{-5}$ & $1.95 \times 10^{-2}$ \\
\hline & ptc-miR395b & ctgaagtgtttgggggaactc & 0.17 & down & $5.45 \times 10^{-5}$ & $1.53 \times 10^{-2}$ \\
\hline & chr13_29473_mature & ttttggtcggtatgtcttgc & 4.39 & up & $2.45 \times 10^{-4}$ & $4.02 \times 10^{-2}$ \\
\hline \multirow{10}{*}{ S5 vs. D5 } & chr8_20880_mature & tacacctgacatttatggcat & 6.42 & up & $6.04 \times 10^{-5}$ & $1.70 \times 10^{-2}$ \\
\hline & chr5_13131_mature & acagaatcagagttcacaggcct & 10.70 & up & $3.07 \times 10^{-6}$ & $3.03 \times 10^{-3}$ \\
\hline & chr17_37159_mature & gcatcaatttatcttagtagcca & 6.90 & up & $1.48 \times 10^{-5}$ & $7.29 \times 10^{-3}$ \\
\hline & chr7_17723_mature & tatgacatcttgatatata & 0.01 & down & $3.43 \times 10^{-18}$ & $6.77 \times 10^{-15}$ \\
\hline & chr7_17886_mature & gtggatcatgtattttgatgg & 5.20 & up & $1.18 \times 10^{-4}$ & $2.91 \times 10^{-2}$ \\
\hline & ptc-miR169t & gagccaagaatgacttgccgg & 0.15 & down & $3.65 \times 10^{-5}$ & $1.44 \times 10^{-2}$ \\
\hline & chr17_37159_star & tgcaatgtagggaatagatgtg & 7.81 & up & $5.05 \times 10^{-5}$ & $1.66 \times 10^{-2}$ \\
\hline & chr3_8559_star & tggcattttctccttttgagttt & 0.14 & down & $1.75 \times 10^{-4}$ & $3.84 \times 10^{-2}$ \\
\hline & chr13_29473_mature & ttttggtcggtatgtcttgc & 6.84 & up & $5.68 \times 10^{-6}$ & $3.73 \times 10^{-3}$ \\
\hline & chr1_2404_mature & acacactgcatctaaaaacta & 5.21 & up & $2.00 \times 10^{-4}$ & $3.94 \times 10^{-2}$ \\
\hline
\end{tabular}

FC: fold change; FDR: false discovery rate; D5, F5, S5 represent diploid, triploid-F, and triploid-S plants in the 5th leaves in the morning, respectively. 
Table 2. Targeted negative regulation relationship in miRNA-mRNA.

\begin{tabular}{|c|c|c|c|c|c|c|c|c|c|c|c|}
\hline Group & miRNA_ID & miRNA_FC & Style & FDR & Target Gene_ID & Gene_FC & Style & FDR & Tair & Symbol & Description \\
\hline \multirow{9}{*}{ F5 vs. D5 } & chr17_37159_star & 9.23 & up & $4.32 \times 10^{-3}$ & Potri.001G375700 & 0.43 & down & $2.44 \times 10^{-2}$ & AT3G15050 & IQD10 & IQ-domain 10 \\
\hline & ptc-miR169t & 0.07 & down & $4.38 \times 10^{-5}$ & Potri.006G053500 & 2.87 & up & $4.10 \times 10^{-3}$ & AT3G14020 & NF-YA6 & nuclear factor $\mathrm{Y}$, subunit A6 \\
\hline & ptc-miR395b & 0.17 & down & $1.53 \times 10^{-2}$ & Potri.010G081200 & 1.53 & up & $2.96 \times 10^{-2}$ & АT3G22890 & APS1 & ATP sulfurylase 1 \\
\hline & ptc-miR395d & 0.19 & down & $1.95 \times 10^{-2}$ & Potri.010G081200 & 1.53 & up & $2.96 \times 10^{-2}$ & AT3G22890 & APS1 & ATP sulfurylase 1 \\
\hline & ptc-miR395f & 0.17 & down & $1.51 \times 10^{-2}$ & Potri.010G081200 & 1.53 & up & $2.96 \times 10^{-2}$ & AT3G22890 & APS1 & ATP sulfurylase 1 \\
\hline & ptc-miR395h & 0.17 & down & $1.51 \times 10^{-2}$ & Potri.010G081200 & 1.53 & up & $2.96 \times 10^{-2}$ & AT3G22890 & APS1 & ATP sulfurylase 1 \\
\hline & ptc-miR395j & 0.20 & down & $3.07 \times 10^{-2}$ & Potri.010G081200 & 1.53 & up & $2.96 \times 10^{-2}$ & AT3G22890 & APS1 & ATP sulfurylase 1 \\
\hline & ptc-miR395k & 0.18 & down & $1.90 \times 10^{-2}$ & Potri.010G081200 & 1.53 & up & $2.96 \times 10^{-2}$ & AT3G22890 & APS1 & ATP sulfurylase 1 \\
\hline & chr5_13131_mature & 7.76 & up & $1.51 \times 10^{-2}$ & Potri.012G083100 & 0.41 & down & $2.78 \times 10^{-2}$ & AT4G10650 & AT4G10650 & $\begin{array}{c}\text { P-loop containing nucleoside } \\
\text { triphosphate hydrolases } \\
\text { superfamily protein }\end{array}$ \\
\hline \multirow{5}{*}{ S5 vs. D5 } & chr7_17886_mature & 5.46 & up & $2.14 \times 10^{-2}$ & Potri.014G185300 & 0.29 & down & $4.25 \times 10^{-2}$ & AT5G42710 & AT5G42710 & unknown protein \\
\hline & chr17_37159_star & 7.81 & up & $1.66 \times 10^{-2}$ & Potri.007G053400 & 0.11 & down & $3.71 \times 10^{-5}$ & AT5G67400 & RHS19 & root hair specific 19 \\
\hline & chr17_37159_star & 7.81 & up & $1.66 \times 10^{-2}$ & Potri.010G239300 & 0.63 & down & $3.89 \times 10^{-2}$ & AT4G39200 & AT4G39200 & Ribosomal protein S25 family protein \\
\hline & chr3_8559_star & 0.14 & down & $3.84 \times 10^{-2}$ & Potri.005G119700 & 4.96 & up & $2.07 \times 10^{-2}$ & AT2G18180 & AT2G18180 & $\begin{array}{l}\text { Sec14p-like phosphatidylinositol } \\
\text { transfer family protein }\end{array}$ \\
\hline & chr5_13131_mature & 10.70 & up & $3.03 \times 10^{-3}$ & Potri.012G083100 & 0.34 & down & $4.87 \times 10^{-3}$ & AT4G10650 & AT4G10650 & $\begin{array}{l}\text { P-loop containing nucleoside } \\
\text { triphosphate hydrolases } \\
\text { superfamily protein }\end{array}$ \\
\hline
\end{tabular}

FC: fold change; FDR: false discovery rate; D5, F5, S5 represent diploid, triploid-F, and triploid-S plants in the 5th leaves in the morning, respectively. ptc- means the miRNAs detecked in Populus trichocarpa miRNA database. Chl_ means the novel miRNA for Populus cathayan. 


\section{Discussion}

\subsection{Temporal Differences in Gene Expression Patterns in Populus Allotriploid Plants}

In this study, the same cultivation environment and sampling time were used for both triploid and diploid plants. When the diploid was used as a control, the DEGs from triploid-F and triploid-S were different, and so were the DEG sets from various leaf canopy positions in triploids (Figure S2). Only 6.3-47.2\% of genes showed a dosage effect on pathways directly related to vegetative growth (Table S4). The DEGs related to chlorophyll synthesis, photosynthesis, and sucrose and starch synthesis and metabolism in different leaves of triploid plants showed several discrepancies (Figure 6). For example, LHCA2 and LHCA6 showed upregulated expression in the 5 th leaves and no difference in the 10th leaves, and LHCA2 had downregulated expression in the 25th leaves of triploid-F plants compared to diploid plants. However, $L H C$ showed no difference in the 5 th leaves and upregulated expression in the 10th leaves, and LHCA2 showed downregulated expression in the 25th leaves of triploid-S plants compared to diploid plants. These differences in gene expression dosage indicated that gene transcription in allotriploid plants had some temporal aspects and patterns. The dosage effect genes that generated the enzyme protein in the metabolic pathway depended on the product formed in the previous stage [21]. The product of the dosage effect genes was the substrate of downstream genes in the next stage of the metabolic pathway [22,23]. The temporal difference in gene expression patterns may be a kind of adaptive behavior for budgeting energy and making full use of the cellular apparatuses in the metabolic process in allotriploid Populus (Figure 7).

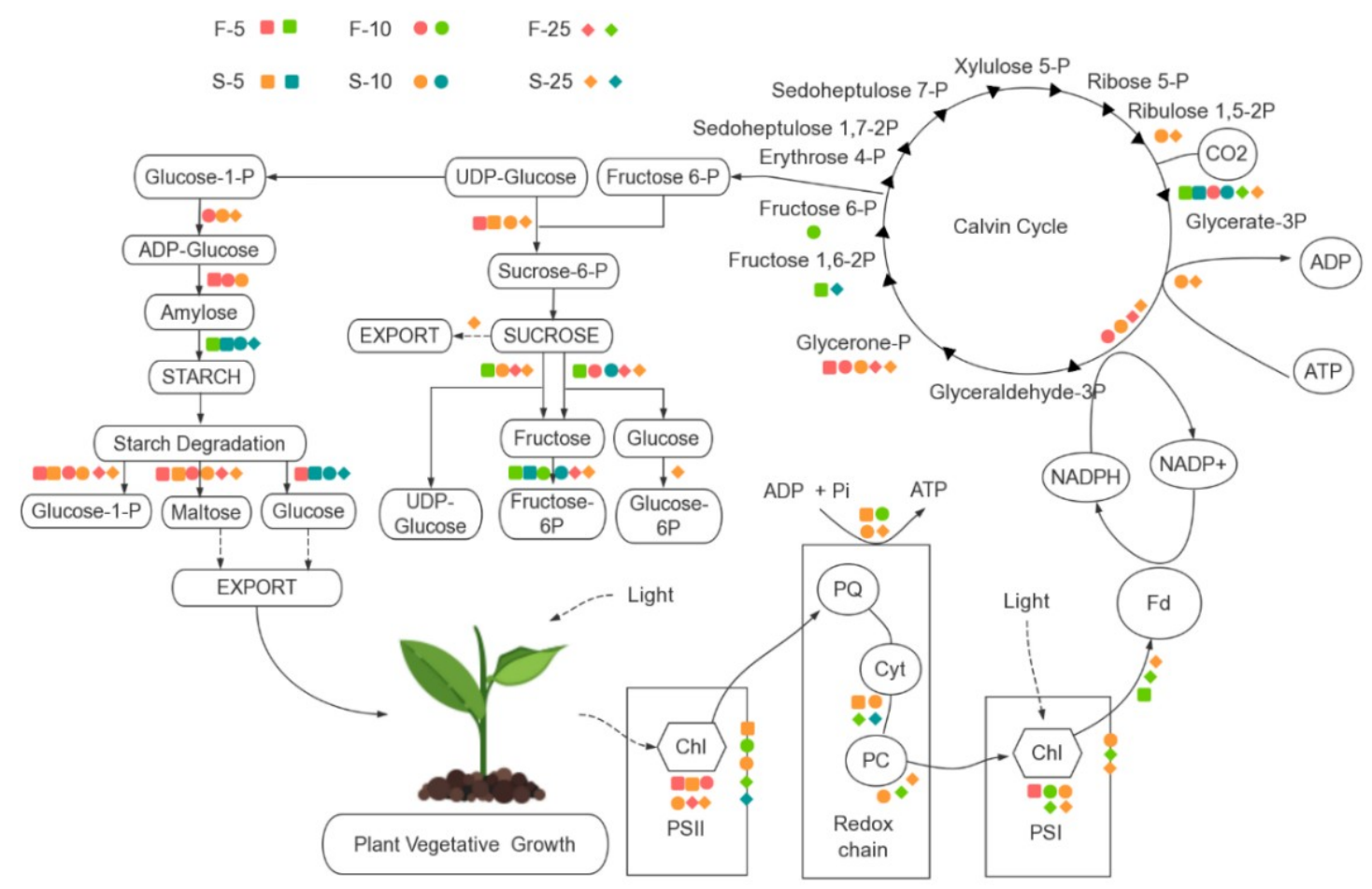

Figure 6. DEGs involved in metabolism pathway in the leaves of triploid-F and triploid-S plants. Warm and cool colors represent upregulated and downregulated expression, respectively. 


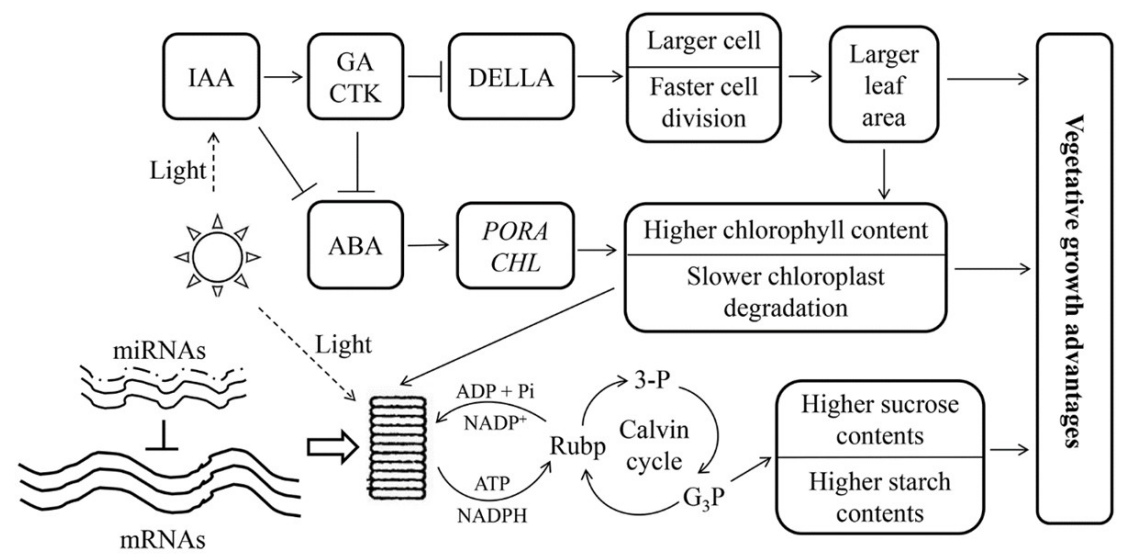

Figure 7. A model of the vegetative growth advantages of Populus allotriploid. Arrows and short-term indicate promotion and inhibition, respectively. The solid lines of mRNAs represent the dosage effect in Populus allotriploid, and the dashed lines of miRNAs represent no dosage effect in Populus allotriploid. 3-P: triphosphoglycerate; $\mathrm{G}_{3} \mathrm{P}$ : triglyceride phosphate.

\subsection{Gene Expression Differences between Populus Allotriploids and Diploids}

The contribution of photosynthesis to plant vegetative growth is largely determined by leaf area, chlorophyll content per leaf area, and chloroplast life span [12,14]. A greater number of chloroplasts and higher chlorophyll content in allotriploids might be a result of the significantly greater expression of protochlorophyllide oxidoreductase (POR) in Populus allotriploids compared to diploids. POR catalyzed the synthesis of tetrapyrrol and promoted protochlorophyllide to make chlorophyll $[14,20]$. Similar results were reported in Arabidopsis tetraploids. The leaf chlorophyll content was higher in Arabidopsis tetraploids than in diploids because of upregulated expression of PORA and PORB in Arabidopsis tetraploids [2]. However, the degradation of chlorophyll and chloroplasts led to leaf senescence directly $[24,25]$. In the present study, the activity of chlorophyllase was weaker in the 25th leaves of triploid-S plants than in diploid plants, and electron microscopy ultrastructure observation showed that degradation of chloroplasts was slower in allotriploid plants. These findings might be related to the chlorophyllase gene $(C L H)$, which regulates the degradation of chlorophyll and was downregulated in the 25th leaves of triploid-S plants compared to diploid plants.

As the main light-capture protein complexes, LHCII controlled light quantum divergence and transfer [26]. In the present study, most of the LHC gene family members showed upregulated expression in allotriploid plants compared to diploid plants, which indicates that light capture was more efficient than in diploid plants. STN7 was an important gene in the process of LHCII phosphorylation and controlled the expression of the photosynthesis gene [27]. Palareti reported that the phosphorylation signal was disturbed in the absence of STN7 mutant materials in Arabidopsis and that efficiency of photosynthesis was altered [28]. STN7 showed upregulated expression in the present triploid plants compared to diploid plants, which indicates that the triploids had a more efficient phosphorylation process compared to the diploids. PSI and PSII were the subunit protein complexes that embedded in the thylakoid membrane (mainly including the Psa and Psb gene families), driving the light reaction [29]. Most members of the Psa and Psb gene families, including PsaK, PsaF, PsbP, and $P s b Q$, were also upregulated in triploid plants compared to diploid plants, which indicates that the light reaction was more efficient in triploids than in diploids.

Starch was the final product of photosynthesis, and more efficient photosynthesis led to the accumulation of the photosynthetic product. To maintain the material balance in cells, sugars and starches need more active catabolism and transfer processes. SUS, SPS, SS, AMS, BAM, and PHS were the main enzymes involved in the synthesis and metabolism of sugar and starch [30]. Enhancing SPS activity increased sucrose content in A. thaliana [31]. Ni found that tetraploids had higher sucrose and starch content and a greater ability to synthesize and decompose starch in A. thaliana. BAM, the 
PHS related to starch decomposition that upregulated expression in A. thaliana tetraploids during the day, resulted in a growth advantage in A. thaliana tetraploids compared to diploids [2]. Allotriploid plants showed higher sugar and starch content, and the enzyme activity of SUS, SPS, and AMS was comparable to that of the diploid in 5th, 10th, and 25th leaves. Moreover, most genes related to enzyme synthesis showed upregulated expression patterns in different leaf positions of Populus allotriploids, indicating vigorous synthesis and decomposition capacity, and efficient sugar transport processes could ensure more energy for growth and development in Populus allotriploids [32-34].

Higher levels of IAA, GAs, CTK, and BRs could promote protein synthesis, cell division, and differentiation; maintain the high growth advantage; and prevent leaf aging [35]. GAs compounded mainly through GA20ox, Ga3ox family members [36]. BRs promoted the photosynthesis and growth rate and coordinated the interaction with IAA [37]. A transcription factor, $B Z R 1$, involved in the BRs signal transduction [38]. The genes GA20ox2, GA20ox4, GA3ox1, BZR, and BRI, which were related to the synthesis and response of ZT, BRs, IAA, and GAs, were significantly upregulated in allotriploid plants compared to diploid plants. The result was that IAA, ZT, and GA3 content was higher in allotriploid plants compared to diploid plants. Therefore, triploids had a greater ability to undergo cell division than diploids (Figure 7).

\subsection{Expression of Negative Regulatory Factors in Populus Allotriploids}

As a type of negative regulatory factors, miRNAs inhibited the expression of their target genes usually through perfect or nearly perfect complementation with target gene sequences [39]. In the present study, 10-12 differentially expressed miRNAs were detected in 3181 miRNAs from triploid-F and triploid-S plants compared to diploid plants, respectively, and failed to find target genes significantly associated with vegetative growth. The expression of miRNAs related to chlorophyll synthesis and decomposition, photosynthesis, and sugar and starch synthesis and decomposition did not differ between allotriploid and diploid plants, which demonstrated that the expression of miRNAs related to vegetative growth in the leaves of Populus allotriploids showed no dosage effect. Similarly, 2273 detected miRNAs showing no significant differences in expression between allotriploid and diploid plants were reported by Suo on the terminal bud of the same origin used in this study [19].

The circadian clock had a regulatory role in polyploid growth advantage. It impacted oscillator or signal systems in higher plants, but the molecular regulating mechanisms are still unclear. The circadian clock regulated gene expression by regulating circadian rhythms and significantly affected plant growth and development [40]. Ni showed that CCA1 and $L H Y$, which are upstream of transcription factors, were more inhibited during the day in Arabidopsis allotriploids than in diploids [2]. This allowed for the expression of regulon TOC1 and GI, and then downstream genes were upregulated, including genes related to chlorophyll synthesis, photosynthesis, and sucrose and starch metabolism. We believed that there was a connection between the circadian clock and vegetative growth in Arabidopsis and that polyploid plants could better use the daytime light. In the present study, expression of $L H Y$ in the 5th leaves at 9:00 am in Populus allotriploids at various leaf canopy positions did not differ from that of diploids (Table S5). Expression of TOC1 and GI did not differ between allotriploid and diploid plants. There were no homologous genes of A. thaliana CCA1 in Populus leaves, which suggest inhibition of CCA1 might not work in Populus allotriploids. Our results indicated that different regulatory mechanisms might exist in different species in circadian clock gene expression in polyploid plants.

\section{Materials and Methods}

\subsection{Plant Materials}

Populus allotriploid populations $(2 \mathrm{n}=3 \times=57)$ were generated from the hybridization of induced 2n female gametes of Populus pseudosimonii $\times$ P. nigra 'Zheyin3\#' and P. $\times$ beijingensis. The allotriploid plants divided into first-division restitution types and second-division restitution $2 \mathrm{n}$ megaspore types according to Dong's methods $[20,41]$. The allotriploid population that originated from first-division 
restitution $2 \mathrm{n}$ female gametes was named "triploid- $\mathrm{F}$ ", and the population derived from second-division restitution $2 \mathrm{n}$ female gametes was named "triploid-S". The diploid population originating from the same parents was used as a baseline control. The origin of materials used in the present research are shown in Figure S3. Nine seedings were randomly selected in each population and cultivated in greenhouse from previous results [13]. Three position leaves (5th, 10th, 25th leaf from stem apex) were collected from healthy tissue seedlings grown for 3 months. Equal amounts of the leaves from three diploid (or alltriploid) same position were mixed as one sample. Three biological replicates were used for each genotype.

\subsection{Transcriptome Analysis}

The 5th, 10th, and 25th leaf samples used for genome-wide transcriptome sequencing in the triploid-F, triploid-S, and diploid plants were harvested and placed into cryopreserved tubes and then quickly frozen in liquid nitrogen. A TRIzol reagent kit (Invitrogen, Carlsbad, CA, USA) was used to extract the total RNA in leaf samples, and an RNase-Free DNaseSet (Qiagen China, Shanghai, China, https://www.qiagen.com/cn/) was used to purify the RNA. To detect the integrity of the RNA, we performed agarose gel electrophoresis, and a NanoDrop 2000 biological analyzer (Thermo Fisher Scientific Inc., Wilmington, DE, USA) was used to detect the concentration of RNA. After this quality control check $(1.6 \leq 28 \mathrm{~s} / 18 \mathrm{~s} \leq 2.0)$, high-quality RNA was used for subsequent sequencing. We built mixed gene pools using a mixture of three candidate genotypes in the 5th, 10th, and 25th leaves of triploid-F, triploid-S, and diploid plants, respectively, with three biological duplications. Following Wang et al., [42], an Ion total RNA-Seq Kit v2 (Life Technologies, Santa Clara, CA, USA) was used to build the cDNA libraries at different leaf positions. Transcriptome sequencing of leaf samples was performed on the Ion Proton platform (Life Technologies) by Shanghai Novelbio Biological Technology Co., Ltd. (Shanghai, China, http://www.novelbio.com/). Original reads less than $50 \mathrm{bp}$ were filtered out, and the rest were mapped to the genome of Populus trichocarpa using MapSplice [43]. The abundance of transcription was shown by reads per kilobase per million mapped reads (RPKM). DESeq R package was applied for differential gene expression analysis [44]. The resulting $p$-values were adjusted by Benjamini and Hochberg' approach for controlling false discovery rate [45]. Genes with adjusted $p$-value $<0.05$ and fold changes $\left|\log _{2}(\mathrm{FC})\right|>1$ were considered as differentially expressed. Information on gene annotation was acquired from the NCBI (http://www.ncbi.nlm.nih.gov/), JGI (http://jgi.doe.gov/), PopGenie (http://popgenie.org/), Tair (http://www.arabidopsis.org/), and KEGG (http://www.kegg.jp/) databases.

\subsection{RT-PCR Validation of Differentially Expressed Genes}

A FastQuant RT kit (with gDNase; Tiangen Biotech Co., Ltd., Beijing, China) was used to perform the reverse transcription reaction. Real-time polymerase chain reaction (RT-PCR) was accomplished using a SuperReal PreMix Plus (SYBR Green, Beijing, China) kit (Tiangen Biotech, Beijing, China) using an Applied Biosystems 7500 Fast instrument (AB Ltd., Lincoln, NE, USA). The RT-PCR master mix included $10 \mu \mathrm{L} 2 \times$ SuperReal PreMix Plus, $0.6 \mu \mathrm{L}$ forward primer, $0.6 \mu \mathrm{L}$ reverse primer, $2 \mu \mathrm{L}$ cDNA template, $0.4 \mu \mathrm{L} 50 \times$ ROX Reference Dye, and $6.4 \mu \mathrm{L}$ RNase-free ddH2O. RT-PCR was performed using 39 cycles of the following conditions: $95^{\circ} \mathrm{C}$ for $15 \mathrm{~min}$ for pre-degeneration, $95^{\circ} \mathrm{C}$ for $10 \mathrm{~s}$ for degeneration, $58^{\circ} \mathrm{C}$ for $30 \mathrm{~s}$ for annealing, $72{ }^{\circ} \mathrm{C}$ for $30 \mathrm{~s}$ for extension. Afterward the samples were heated to $95^{\circ} \mathrm{C}$ for $15 \mathrm{~s}$ and then $60^{\circ} \mathrm{C}$ for $1 \mathrm{~min}$ for dissolution curve analysis. Four technical replicates and three biological replicates were used for each sample and randomly selected gene. The sequences of primers used in the present study were designed using Primer3Plus (http://www.primer3plus.com/) and were listed in Table S6. Actin (accession number: EF145577) was chosen as the reference gene, and the $-2^{-\Delta \Delta C t}$ method was used to calculate gene expression. 


\subsection{Measurement of Photosynthesis}

Pn was determined on the first fully expanded leaf to the last leaf from the top of the stem in the three highest Pn genotypes using the LI-6400-02B portable photosynthesis system (LiCor, Lincoln, NE, USA). Measurements were taken on sunny days at 08:30-11:30 a.m., with maintenance of the photosynthetic photon flux density at $1400 \mu \mathrm{mol}$ (photon) $\mathrm{m}^{-2} \cdot \mathrm{s}^{-1}$ and a $\mathrm{CO}_{2}$ concentration of $400 \mu \mathrm{mol}$ $\mathrm{mol}^{-1}$, relative air humidity of $60-65 \%$, and flow of $500 \mu \mathrm{mol} \cdot \mathrm{mol}^{-1}$.

\subsection{Measurement of Chlorophyll, Starch and Sugar Content}

Chlorophyll, starch, and sugar content were measured in the 5th, 10th, and 25th leaves of the three selected candidate genotypes using three biological replicates. Chlorophyll content was determined as described by Vernon \& Seely [46] with slight modifications. A total of $1 \mathrm{~g}$ fresh leaf tissue was ground into a homogenate with $5 \mathrm{~mL} 95 \%$ ethanol with a small quantity of quartz sand and calcium carbonate powder. Then the homogenate was ground in an additional $5 \mathrm{~mL} \mathrm{95 \%} \mathrm{ethanol.} \mathrm{After} \mathrm{standing} \mathrm{for} 3 \mathrm{~min}$, the extract was filtered to a $50 \mathrm{~mL}$ brown volumetric flask, diluted with $95 \%$ ethanol to $50 \mathrm{~mL}$, and then mixed. The absorbance of the filtrate was measured at 645 and $663 \mathrm{~nm}$ using a spectrophotometer (Ultrospec 6300 Pro, Cambridge, UK). Chlorophyll content was calculated as follows: chlorophyll content $\left(\mathrm{mg} \cdot \mathrm{g}^{-1}\right)=8.02 \times \mathrm{A} 663+20.20 \times \mathrm{A} 645$.

Starch and sugar contents were also measured in the 5th, 10th, and 25th leaves of triploid-F, triploid-S, and diploid plants. Then $10 \%$ of the crude extract was homogenized with $0.1 \mathrm{~g}$ powdered fresh leaf tissue in $0.9 \mathrm{~mL} 1 \times$ phosphate buffer $(\mathrm{pH} 7.2)$. Starch, sucrose, fructose, and glucose content was determined using EnzyChrom ${ }^{\mathrm{TM}}$ assay kits (BioAssay Systems Co., Hayward, CA, USA, https://www.bioassaysys.com/) and expressed as milligrams of substance per gram of fresh leaf.

\subsection{Enzyme Assay}

Similar to the determination of starch and sugar content, $10 \%$ of the enzymatic crude extract of the 5th, 10th, and 25th leaves of triploid-F, triploid-S, and diploid plants were prepared. Sucrose synthase (SUS), sucrose phosphate synthase (SPS), and amylase (AMS) activities were assayed using enzyme-linked immunosorbent assay (ELISA) kits (Comin Commodities Co., Ltd., Zhejiang, China, http://www.comin.biz/index.html). Chlorophyllase activity was determined using a chlorophyllase ELISA kit (GeneTex, Inc., Irvine, CA, USA, http://www.genetex.com/).

\subsection{Plant Materials}

The ultrastructure of chloroplasts in the 5th, 10th, and 25th leaves was manufactured using the method of Otegui et al. [47] with minor modifications. Leaf samples were sectioned with a razor blade into small pieces of $2 \times 2 \mathrm{~mm}$ and rapidly infiltrated with $2.5 \%$ glutaraldehyde for $4 \mathrm{~h}$. After being dipped in $1 \times$ phosphate buffer three times for 30 min each time, leaves were infiltrated into $1 \% \mathrm{OsO}_{4}$ for $2 \mathrm{~h}$, then washed with $1 \times$ phosphate buffer for $30 \mathrm{~min}$ each time. The leaves were dehydrated for $20 \mathrm{~min}$ in $30 \%, 50 \%, 70 \%$, and $90 \%$ acetone, followed by two washes with $100 \%$ acetone. After dehydration, the leaves were infiltrated twice for $12 \mathrm{~h}$ with $100 \%$ acetone mixed with $25 \%, 50 \%$, 75\%, or $100 \%$ resin. Afterward, leaves were placed into an embedding plate with fresh resin, and polymerization was carried out at $60{ }^{\circ} \mathrm{C}$ for $12 \mathrm{~h}$, followed by cooling at room temperature. Aggregation blocks were cut into slices of $1 \mu \mathrm{m}$ thickness using an ultra-thin slicing machine (Leica EM UC7, Berlin, Germany). Sections were stained with $2 \%$ uranium acetate in $70 \%$ methanol for 10 min followed by Reynold's lead citrate (2.6\% lead nitrate and 3.5\% sodium citrate, $\mathrm{pH} 12)$ for $5 \mathrm{~min}$. The chloroplast ultrastructure was observed through a JEM-1010 electron microscope (Jeol Ltd., Tokyo, Japan).

\subsection{Determination of Plant Endogenous Hormone Content}

Plant endogenous hormone content, including gibberellic acid (GA3), auxin (IAA), zeatin (ZT), and abscisic acid (ABA), was determined in the 5th and 25th leaves of triploid-F and diploid plants 
using the high-performance liquid chromatography-mass spectrometry (LC-MS) method as described in Pan et al. [48]. Leaves were harvested, immediately frozen in liquid nitrogen, and then transferred to $\mathrm{a}-80^{\circ} \mathrm{C}$ refrigerator. The leaf tissue of each sample was ground to powder in liquid nitrogen, and $50 \mathrm{mg}$ powder was transferred into a $2 \mathrm{~mL}$ centrifuge tube, followed by the addition of $500 \mu \mathrm{L}$ extraction agent (2-isopropyl alcohol:water:hydrochloric acid = 2:1:0.002). The internal standard solution of plant hormone contained $2 \mathrm{ng} / \mu \mathrm{L} \mathrm{GA}_{3} 5 \mu \mathrm{L}, 2 \mathrm{ng} / \mu \mathrm{L}$ IAA $5 \mu \mathrm{L}, 0.25 \mathrm{ng} / \mu \mathrm{L}$ ABA $15 \mu \mathrm{L}$, and $0.25 \mathrm{ng} / \mu \mathrm{L} \mathrm{ZT}$ $10 \mu \mathrm{L}$. Then we placed the centrifuge tubes on a rolling bed at $4{ }^{\circ} \mathrm{C}, 100 \times g$, for $30 \mathrm{~min}$ before adding $1 \mathrm{~mL}$ methylene chloride to each tube. The tubes were shaken for an additional $30 \mathrm{~min}$, and the mixed solution was centrifuged at $4{ }^{\circ} \mathrm{C}, 12,000 \times g$, for $10 \mathrm{~min}$. The lower fraction was transferred to a clean centrifuge tube and dried with nitrogen gas. Then, $200 \mu \mathrm{L}$ methanol was added to dissolve the leaf sample. A $10 \mu \mathrm{L}$ sample was used for LC-MS using an AB Sciex QTRAP 5500 LC system (AB Sciex Pte., Ltd., South Burlington, Vermont, USA), with acetonitrile and $0.4 \%$ triethylamine solution ( $\mathrm{pH}$ 3.5) used as the mobile phase. We used biological replicates (samples) for each genotype, and each replicate was performed with three technical replicates.

\section{9. miRNAs Analysis}

Samples of the 5th leaves of triploid-F, triploid-S, and diploid plants were taken at 9:00 a.m. and frozen in liquid nitrogen. An RNA 6000 Nano Assay Kit and 2100 Bioanalyzer RNA Nanochip (Agilent) were used to control the quality of purity and concentration of RNA, respectively (RIN $\geq 8.0$ ), and a miRNeasy Mini Kit (Qiagen, shanghai, China) was used to purify the RNA. Similar to transcriptome sequencing, miRNA sequencing was completed on the Ion Proton platform (Life Technologies) by Shanghai Novelbio Biological Technology after the cDNA libraries were built using a mixture of the three candidate genotypes of triploid-F, triploid-S, and diploid plants, respectively. High-quality reads after filtering were mapped to the miRNA database of Populus trichocarpa (Release 21.0, http://www.mirbase.org/) using BWA (v0.7.5a). To obtain the new candidate miRNA precursor, unmapped reads were further mapped to the genome of $P$. trichocarpa. To obtain more homologous miRNAs, unmapped reads were mapped one by one onto the miRNA databases of Arabidopsis thaliana, Glycine max, Zea mays, and Oryza sativa. The target genes of miRNAs were predicted using psRNATarget (plantgrn.noble.org/psRNATarget).

\section{Conclusions}

In summary, different vegetative growth advantages in polyploid plants formed as a result of different regulatory mechanisms. A new molecular regulatory mechanism of vegetative growth advantage in allotriploid plants was discovered in the present study. The expression of genes related to vegetative growth had a dosage effect, whereas the expression of related miRNAs showed no dosage effect in Populus allotriploids. Gene transcription and dosage expression were time-dependent. In addition, gene expression levels inhibited by miRNAs were lower, leading to less negative control in target genes by miRNAs in Populus allotriploids compared to diploids. Furthermore, the leaf area was bigger and the chloroplast aging rate was slower in allotriploids than in diploids, leading to augmented effects of light reaction; carbon fixation; sucrose and starch synthesis and metabolism; and synthesis of IAA, CTK, and GA3 in allotriploids compared to diploids. All of these findings together promote a vegetative growth advantage in Populus allotriploids .

Supplementary Materials: Supplementary materials can be found at http://www.mdpi.com/1422-0067/21/2/441/s1.

Author Contributions: T.L. and K.D. contributed significantly to most of the experiment, analysis and manuscript preparation, performed the data analyses and wrote the manuscript. Y.R. examined part of the gene expression, chlorophyll, starch and sugars contents. X.G. conducted the statistical tests, examples and enzyme activities detection. X.K. contributed to the conception of the study, revision of the manuscript and funded the study. All authors have read and agreed to the published version of the manuscript.

Funding: This work was supported by the National Natural Science Foundation of China (31530012). 
Acknowledgments: We were grateful to the Hairong Wei, Forestry College, Michigan Tech University, for his helpful suggestions and revision of the manuscript.

Conflicts of Interest: The authors declare no conflict of interest.

\section{Abbreviations}

DEGs Differentially Expressed Genes

CTK Cytokinins

BRs Brassinosteroid

\section{References}

1. Chen, Z.J. Genetic and epigenetic mechanisms for gene expression and phenotypic variation in plant polyploids. Annu. Rev. Plant Biol. 2007, 58, 377-406. [CrossRef] [PubMed]

2. Ni, Z.; Kim, E.-D.; Ha, M.; Lackey, E.; Liu, J.; Zhang, Y.; Sun, Q.; Chen, Z.J. Altered circadian rhythms regulate growth vigour in hybrids and allopolyploids. Nature 2009, 457, 327-331. [CrossRef] [PubMed]

3. Auger, D.L.; Gray, A.D.; Ream, T.S.; Kato, A.; Coe, E.H.; Birchler, J.A. Nonadditive gene expression in diploid and triploid hybrids of maize. Genetics 2005, 169, 389-397. [CrossRef] [PubMed]

4. Guo, M. Allelic variation of gene expression in maize hybrids. Plant Cell Online 2004, 16, 1707-1716. [CrossRef] [PubMed]

5. Kondorosi, E.; Roudier, F.; Gendreau, E. Plant cell-size control: Growing by ploidy? Curr. Opin. Plant Biol. 2000, 3, 488-492. [CrossRef]

6. Müntzing, A. The chromosomes of a giant populus tremula. Hereditas 1936, 21, 383-393. [CrossRef]

7. Zhu, Z.; Lin, H.; Kang, X.; Zhu, Z.T.; Lin, H.B.; Kang, X.Y. Study on allotriploid breeding of Populus tomentosa B301 and other clones. Sci. Silvae Sin. 1995, 31, 499-505.

8. Warner, D.A.; Ku, M.S.B.; Edwards, G.E. Photosynthesis, leaf anatomy, and cellular constituents in the polyploid C4 grass panicum virgatum. Plant Physiol. 2008, 84, 461-466. [CrossRef]

9. Warner, D.A.; Edwards, G.E. Effects of polyploidy on photosynthesis. Photosynth. Res. 1993, 35, $135-147$. [CrossRef]

10. Evans, J.R.; von Caemmerer, S. Enhancing photosynthesis. Plant Physiol. 2011, 155, 19. [CrossRef]

11. Evans, J.R. Improving photosynthesis. Plant Physiol. 2013, 162, 1780-1793. [CrossRef] [PubMed]

12. Offermann, S.; Peterhansel, C. Can we learn from heterosis and epigenetics to improve photosynthesis? Curr. Opin. Plant Biol. 2014, 19, 105-110. [CrossRef] [PubMed]

13. Liao, T.; Cheng, S.; Zhu, X.; Min, Y.; Kang, X. Effects of triploid status on growth, photosynthesis, and leaf area in Populus. Trees Struct. Funct. 2016, 30, 1137-1147. [CrossRef]

14. Apel, K.; Kloppstech, K. The effect of light on the biosynthesis of the light-harvesting chlorophyll a/b protein-Evidence for the requirement of chlorophyll a for the stabilization of the apoprotein. Planta 1980, 150, 426-430. [CrossRef] [PubMed]

15. Corneillie, S.; De Storme, N.; Van Acker, R.; Fangel, J.U.; De Bruyne, M.; De Rycke, R.; Geelen, D.; Willats, W.G.T.; Vanholme, B.; Boerjan, W. Polyploidy affects plant growth and alters cell wall composition. Plant Physiol. 2019, 179, 74-87. [CrossRef]

16. te Beest, M.; Le Roux, J.J.; Richardson, D.M.; Brysting, A.K.; Suda, J.; Kubesova, M.; Pysek, P. The more the better? The role of polyploidy in facilitating plant invasions. Ann. Bot. 2012, 109, 19-45. [CrossRef]

17. Madlung, A.; Doerge, R.W.; Colot, V.; Martienssen, R.A.; Osborn, T.C.; Chris Pires, J.; Birchler, J.A.; Auger, D.L.; Jeffery Chen, Z.; Lee, H.-S.; et al. Understanding mechanisms of novel gene expression in polyploids. Trends Genet. 2003, 19, 141-147.

18. El Baidouri, M.; Kim, K.D.; Abernathy, B.; Li, Y.-H.; Qiu, L.-J.; Jackson, S.A. Genic C-methylation in soybean is associated with gene paralogs relocated to transposable element-rich pericentromeres. Mol. Plant 2018, 11, 485-495. [CrossRef] [PubMed]

19. Suo, Y.; Min, Y.; Dong, C.; Wang, Y.; Cheng, S.; Kang, X. MicroRNA expression changes following synthesis of three full-sib Populus triploid populations with different heterozygosities. Plant Mol. Biol. 2017, 95, $215-225$. [CrossRef]

20. Dong, C.B.; Suo, Y.J.; Wang, J.; Kang, X.Y. Analysis of transmission of heterozygosity by 2 n gametes in Populus (Salicaceae). Tree Genet. Genomes 2015, 11, 799. [CrossRef] 
21. Chen, Z.J. Molecular mechaisms of polyploidy vigor. Trends Plant Sci. 2010, 15, 57. [CrossRef] [PubMed]

22. Song, Q.; Chen, J.Z. Epigenetic and developmental regulation in plant polyploids. Curr. Opin. Plant Biol. 2015, 24, 101-109. [CrossRef] [PubMed]

23. Shi, X.; Zhang, C.; Ko, D.K.; Jeffrey Chen, Z. Genome-wide dosage-dependent and-independent regulation contributes to gene expression and evolutionary novelty in plant polyploids. Mol. Biol. Evol. 2015, 32, 2351-2366. [CrossRef] [PubMed]

24. Griffiths, W.T. Reconstitution of chlorophyllide formation by isolated etioplast membranes. Biochem. J. 2015, 174, 681-692. [CrossRef] [PubMed]

25. Xu, B.; Li, H.; Li, Y.; Yu, G.; Zhang, J.; Huang, B. Characterization and transcriptional regulation of chlorophyll $\mathrm{b}$ reductase gene NON-YELLOW COLORING 1 associated with leaf senescence in perennial ryegrass (Lolium perenne L.). Environ. Exp. Bot. 2018, 149, 43-50. [CrossRef]

26. Sacharz, J.; Giovagnetti, V.; Ungerer, P.; Mastroianni, G.; Ruban, A.V. The xanthophyll cycle affects reversible interactions between PsbS and light-harvesting complex II to control non-photochemical quenching. Nat. Plants 2017, 3, 16225. [CrossRef] [PubMed]

27. Bonardi, V.; Pesaresi, P.; Becker, T.; Schleiff, E.; Wagner, R.; Pfannschmidt, T.; Jahns, P.; Leister, D. Photosystem II core phosphorylation and photosynthetic acclimation require two different protein kinases. Nature 2005, 437, 1179-1182. [CrossRef]

28. Palareti, G.; Legnani, C.; Cosmi, B.; Antonucci, E.; Erba, N.; Poli, D.; Testa, S.; Tosetto, A. Comparison between different $\mathrm{D}$-Dimer cutoff values to assess the individual risk of recurrent venous thromboembolism: Analysis of results obtained in the DULCIS study. Int. J. Lab. Hematol. 2016, 38, 42-49. [CrossRef]

29. Ben-Shem, A.; Frolow, F.; Nelson, N. Crystal structure of plant photosystem I. Nature 2003, 426, 630-635. [CrossRef]

30. Smith, D.M.; Inman-Bamber, N.G.; Thorburn, P.J. Growth and function of the sugarcane root system. Field Crop. Res. 2005, 92, 169-183. [CrossRef]

31. Park, J.-Y.; Canam, T.; Kang, K.-Y.; Ellis, D.D.; Mansfield, S.D. Over-expression of an arabidopsis family a sucrose phosphate synthase (SPS) gene alters plant growth and fibre development. Transgenic Res. 2008, 17, 181-192. [CrossRef] [PubMed]

32. Wang, Z.; Fan, G.; Dong, Y.; Zhai, X.; Deng, M.; Zhao, Z.; Liu, W.; Cao, Y. Implications of polyploidy events on the phenotype, microstructure, and proteome of Paulownia australis. PLoS ONE 2017, 12, e0172633. [CrossRef] [PubMed]

33. Li, A.; Liu, D.; Wu, J.; Zhao, X.; Hao, M.; Geng, S.; Yan, J.; Jiang, X.; Zhang, L.; Wu, J.; et al. MRNA and small RNA transcriptomes reveal insights into dynamic homoeolog regulation of allopolyploid heterosis in nascent hexaploid wheat. Plant Cell 2014, 26, 1878-1900. [CrossRef] [PubMed]

34. Kashkush, K.; Feldman, M.; Levy, A.A. Gene loss, silencing and activation in a newly synthesized wheat allotetraploid. Genetics 2002, 160, 1651-1659.

35. Davies, P.J. The plant hormones: Their nature, occurrence, and functions. In Plant Hormones Biosynthesis, Signal Transduction, Action! Springer: Dordrecht, The Netherlands, 2004; pp. 5-14.

36. Kaneko, M.; Itoh, H.; Inukai, Y.; Sakamoto, T.; Ueguchi-Tanaka, M.; Ashikari, M.; Matsuoka, M. Where do gibberellin biosynthesis and gibberellin signaling occur in rice plants? Plant J. 2003, 35, 104-115. [CrossRef]

37. Halliday, K.J. Plant hormones: The interplay of brassinosteroids and auxin. Curr. Biol. 2004, 14, R1008-R1010. [CrossRef]

38. Yin, Y.; Vafeados, D.; Tao, Y.; Yoshida, S.; Asami, T.; Chory, J. A new class of transcription factors mediates brassinosteroid-regulated gene expression in Arabidopsis. Cell 2005, 120, 249-259. [CrossRef]

39. Llave, C. Endogenous and silencing-associated small RNAs in plants. Plant Cell Online 2002, 14, 1605-1619. [CrossRef]

40. Chen, J.Z.; Birchler, J.A. Polyploid and Hybrid Genomics; Jhon Wiley \& Sons Inc.: Hoboken, NJ, USA, 2013; ISBN 9780470960370.

41. Wang, J.; Li, D.L.; Kang, X.Y. Induction of unreduced megaspores with high temperature during megasporogenesis in Populus. Ann. For. Sci. 2012, 69, 59-67. [CrossRef]

42. Wang, W.; Meng, M.; Zhang, Y.; Wei, C.; Xie, Y.; Jiang, L.; Wang, C.; Yang, F.; Tang, W.; Jin, X.; et al. Global transcriptome-wide analysis of CIK cells identify distinct roles of IL-2 and IL-15 in acquisition of cytotoxic capacity against tumor. BMC Med. Genom. 2014, 7, 49. [CrossRef] 
43. Langmead, B.; Trapnell, C.; Pop, M.; Salzberg, S.L. Ultrafast and memory-efficient alignment of short DNA sequences to the human genome. Genome Biol. 2009, 10, R25. [CrossRef] [PubMed]

44. Wang, L.; Feng, Z.; Wang, X.; Wang, X.; Zhang, X. DEGseq: An R package for identifying differentially expressed genes from RNA-seq data. Bioinformatics 2010, 26, 136-138. [CrossRef] [PubMed]

45. Benjamini, Y.; Hochberg, Y. Controlling the false discovery rate: A practical and powerful approach to multiple testing. J. R. Stat. Soc. Ser. B 1995, 57, 289-300. [CrossRef]

46. Vernon, L.P.; Seely, G.R. The Chlorophylls; Academic Press: Cambridge, MA, USA, 2016; ISBN 1483267725.

47. Otegui, M.S.; Noh, Y.S.; Martínez, D.E.; Vila Petroff, M.G.; Staehelin, L.A.; Amasino, R.M.; Guiamet, J.J. Senescence-associated vacuoles with intense proteolytic activity develop in leaves of Arabidopsis and soybean. Plant J. 2005, 41, 831-844. [CrossRef]

48. Pan, X.; Welti, R.; Wang, X. Quantitative analysis of major plant hormones in crude plant extracts by high-performance liquid chromatography-mass spectrometry. Nat. Protoc. 2010, 5, 986-992. [CrossRef]

(C) 2020 by the authors. Licensee MDPI, Basel, Switzerland. This article is an open access article distributed under the terms and conditions of the Creative Commons Attribution (CC BY) license (http://creativecommons.org/licenses/by/4.0/). 